\title{
Social Networks: Privacy Granted and the Negative Effects for the Individual and Society
}

\author{
Naif A.N. Alsharabi ${ }^{1}$, Redhwan Qasem Ghaleb ${ }^{2}$ \\ ${ }^{1}$ College of Engineering and IT, Amran University, Amran, Yemen \\ ${ }^{2}$ Department of English Language, Amran University, Yemen
}

\begin{abstract}
Undoubtly, social networking has brought a quantum leap in the field of communication over the world. It has overcome many difficulties in the process of communication among the various individuals at the local, regional and global level. Its advantages and virtues are countless. Yet, these advantages may vanish when subscriber's privacies affect negatively the individuals, gr oups or companies. Granting these privacies to subscribers to withhold some information like list of friends, sites visited, and comments and so on leads to major disasters and causes great pain to families and communities. It has brought about a great loss and exploitation of families teens by extremist ideas that lead to terror acts. The privacy bestowed by social networking to the subscribers to conceal some information has violated intentionally or unintentionally the rights of family and society in parental control. To avoid these risks and to reduce them, privacies must be limited and made public.
\end{abstract}

Keywords: social media, disastrous effects, social privacy, social risks

\section{Introduction}

Social media are computer mediated tools that allow people or companies to create, share, or exchange information, career interests, ideas, and pictures, videos in virtual communities and networks, [1]. Yet, the purpose of creating social networks is to keep friends, neighbors and relatives in touch with each other. Much of the people, if not all at the present time and in the light of the evolution of digital technology have accounts at any site of social networking scattered on the World Wide Web. There is an intense competition between networks companies in order to gather a large number of subscribers. The criteria of the successful companies consist in attracting a huge number of subscribers all over the globe. The most prominent of those companies are Facebook Inc, Twitter, Instagram, and others.

But the focus of this research will be on the first three companies. Those companies have been able to occupy an important position in the World Wide Web. The idea of the Facebook site has been lunched at the hand of an American student named Mark Zuckerberg who was studying computer science at Harvard University, USA. In the beginning, the idea was simple intended to collect pictures of college graduates in 2003[2]. Then, it has developed and evolved with Marc till he has created a professional site in 2006[3], allowing a large number of people who have emails and those who are eighteen years old to enter the site and create accounts. They can subsequently communicate with other subscribers and friends sharing photos, video, social and political pages and much more. Facebook site allows many options, including advanced audio and visual conversation and communication between subscribers worldwide. Twitter is ranked second among the most important social sites i.e Facebook in terms of fame and proliferation [4]. It has been founded by an American businessman named Jack Dorsey [5][6], where the location on the idea of sending Tweets reflects people's ideas and touring in their mind or express their condition in given moment, where tweets placed any statement of not more than one hundred and forty characters and shared by the account holder with other subscribers and friends. Instagram is a specialized site originally to displays images and videos of high technology, large and clear, and allows the exchange of media and share them among a group of participants in the site, and allow for filtering technology on them, and it has been added to the site many services and advanced options so that it resembles the social networks[7].

No doubt social networking has brought a quantum leap in the field of communication and surmounted many difficulties in the process of communication among the various individuals at the local, regional and global level. Its advantages and virtues is countless. It introduces substantial and pervasive changes to communication between businesses, organizations, communities, and individuals [8].

The most important advantage is that it has enabled a person to communicate with friends whom he has lost his contact with for a long time. This feature has made the impossible possible through reaching friends of childhood, school, university and work stage. It also has a great role in cultural development and cognitive abilities of individuals and communities. However, those features and benefits may fade in the blink of an eye when privacies affect negatively individuals, groups, companies and institutions and this is the focus of this study.

This paper is an attempt to shed light on the effects of the social media on the ethics, morality and wrong behaviors of the people, irrespective of their color, creed, culture, gender, age, education and profession. It discusses some authority and privacy in order to achieve a better use of social media and avoid negative effects on the individual and community as a result of misusing technology. 


\section{International Journal of Science and Research (IJSR) \\ ISSN (Online): 2319-7064}

Index Copernicus Value (2013): 6.14 | Impact Factor (2014): 5.611

\section{Social Media -Security Thread}

There are dangers associated with social networking including data theft and viruses, which are on the rise. The most prevalent danger though often involves online predators or individuals who claim to be someone that they are not. There are a lot of security thread such as security challenges that belong to social networking sites Nord, for example, but not limited to data theft, counterfeit, theft accounts, an attempt repeated by malicious intrusions, identity theft and so on of the challenges of social networking companies seeking to reduce them has succeeded in doing so although there are some risks, which still represents one of the tools for penetration accounts and violation of privacy supply them.

\subsection{Reset password by Mobile phone}

Figure 1 shows the mobile setting site which can be used to reset an account password via text messages sent to a subscriber's cell phone which is considered a gab exploited by hackers to create fake numbers using certain programs. So that the social media service sends the activation message code to this fake number. Then, the hacker resets the account with a new password.

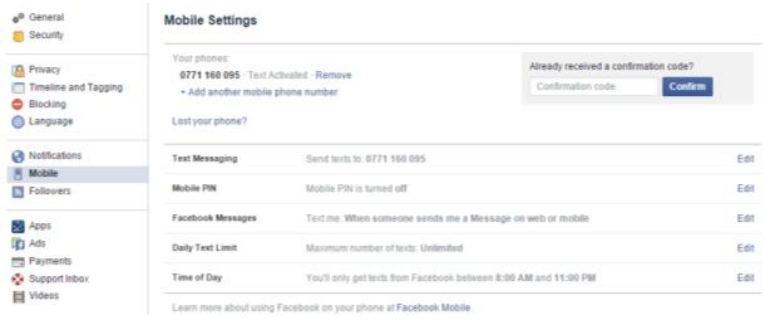

Figure 1: Mobile setting

\subsection{Ads}

There are several ways advertisers can invade your social media privacy, take advantage of your data and make you a target for their ads. Here are the most common ones:

\section{Data Scraping}

It involves tracking people's activities online and harvests personal data and conversations from social media, job websites and online forums. Usually, research companies are the harvesters, and sell the compiled data to other companies. These, in turn, use these details to design targeted ads campaigns for their products. While one might argue that people are knowingly sharing personal details on social media. Thus, it's free for everyone's use, data harvesters don't ask for the owner's consent. And this raises ethics as well as an online privacy problem. One strong case for serious online privacy violation took place in May 2011. Nielsen company [9].

\section{Facebook apps leaking personal data}

It has been reported several times that certain Facebook apps are leaking identifying information about those who are using them, to advertising and Internet tracking companies. And without the users having a clue! Here's how the "leakage" works: during the app's installation process, you are prompted to accept certain terms, and once you click "Allow", the application receives an "access token"[10].

Some of the Facebook apps are leaking these access tokens to advertisers, granting them access to personal-profile data such as chat logs and photos. However, no disclaimer is showed announcing you your data is being transferred to third parties. Thus, your online privacy and safety are put at risk. An example of apps that have been found to leak identifying information include FarmVille and Family Tree [11] .

\section{Online social tracking}

Content maintained in an online social network or other online communities is tracked for changes and updates. The content may include user profiles, digital photos, digital audio and video files, testimonials, and identification of users who are friends. When such change or update occurs, users of the online social network or online community are notified according to various criteria that they have set. The notification may be provided by e-mail, an RSS feed, or a web page when accessed. With this feature, users can browse through content of other users with efficiency [12].

\section{Analysis of the negative aspects of the social media privacy and proposed appropriate solutions}

\subsection{Security and Privacy}

Protection and breakthroughs definition and violation of privacy vary depending on the nature of the use of each class or social, cultural, regional and international component. Most of those groups claim to provide maximum protection for their accounts of intrusion, penetration and access from people so-called hackers, who work tirelessly searching for software gap to access through it to subscriber's accounts and misuse them. With the increase of those breakthroughs, no one can deny that social communication companies (the above-mentioned) have made great and painstaking efforts to overcome those gaps and provided a largely impenetrable protection and this has provided a safe environment for users to freely go through their accounts without fear of penetration. This protection has been increased by linking most of those accounts to personal phone numbers to make sure of the identity of the account holder. However, this preservation can lead to a new way for some people to use it to access the subscribers' accounts (who have lost their phones) and send to the company to reset the password and get through that message to re-activate the account and this causes a lot of problems for some users. In fact, this gap is not considered as a software loophole, but attributes to the owners of these accounts who hold responsibility for any loss of their accounts due to their default. 


\section{International Journal of Science and Research (IJSR) \\ ISSN (Online): 2319-7064}

Index Copernicus Value (2013): 6.14 | Impact Factor (2014): 5.611

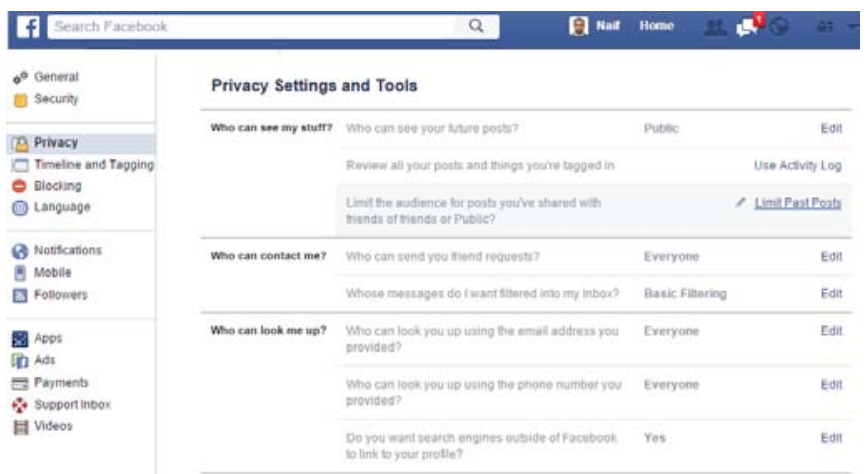

Figure 2: Privacy setting and tools

\subsection{The disastrous effects of the granted privacies}

The most important point which is the core of this study is that the social networking companies are responsible for violating the privacy of individuals and communities as each community has its own customs and traditions that have not been taken into account by those companies. This violation is divided into three categories: the personal freedoms, parental control and community control. Facebook can be taken as an example.

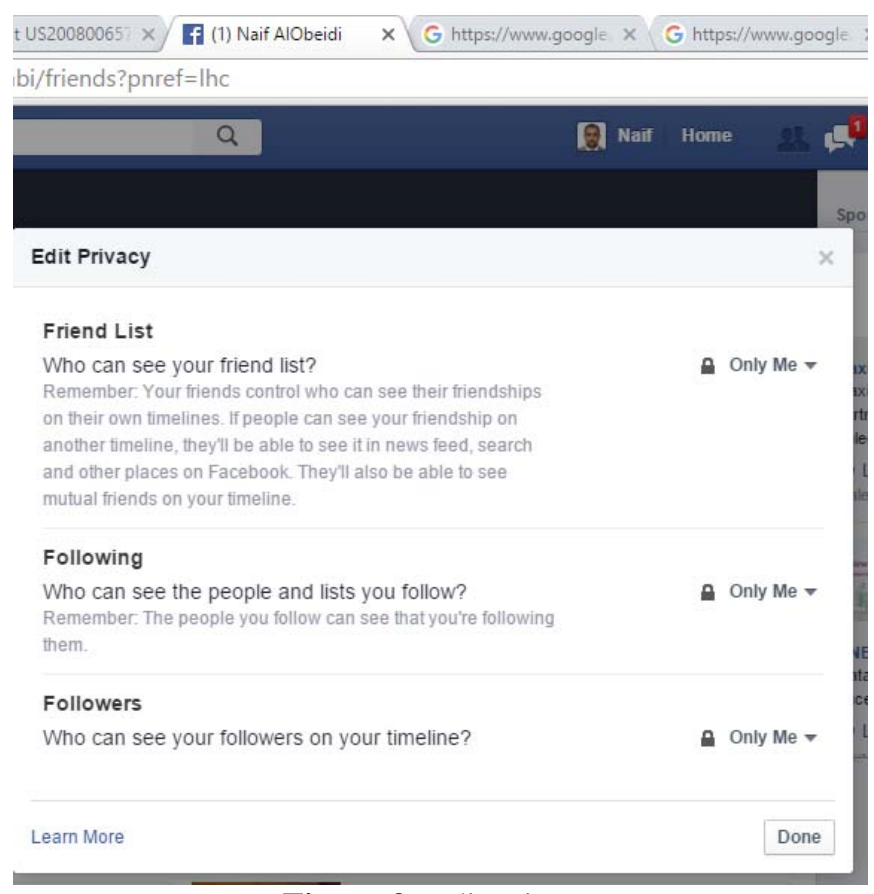

Figure 3: Edit privacy

Facebook company has given subscribers multiple authorities to control the display of their posts and the users are authorized to see these posts, friend's list and sites that have been visited, and many other particulars that were available in the personal pages in general, as shown in figure 2,3. The company has given subscribers' authority to block and hide their personal information like comments, friend's list. They can specify the people who can see or comment their posts. This property is favored by a lot of subscribers who consider it as additional advantage provided by the company. However, this privacy has caused a flagrant violation of the rights of families and communities that prefer to monitor their youth and protect them from suspicious sites that are harmful to their morals, beliefs and ideas.
The family control prevents their members from falling prey to dangerous and fanatic groups who are active through social networks to entrap and use the youth in mischievous acts that affect their communities and families. The best proof of what has been said is that these groups are incriminated today in attracting many of the young men and women and get them embroiled in terror acts in various places around the world. Many of the families hear that their sons or daughters left the house and traveled to an unknown destination and the reason can be ascribed to the social networks, which are the main reason for the absence of family and community control over their members' accounts, because of their inability to follow up their participation and view their friends and sites that are visited. This has created great harm to individuals, families and communities alike.

\subsection{The solution proposed to ideal privacy of subscribers and safety for community}

Many serious attempts have been made to find a way to get what is going on within the social networks, and after strenuous efforts for a long time, we have been able to access and see a number of subscribers' accounts males-females in different areas and have taken copies of their personal chats, posts, comments and sites. In order to complete this study properly and get the accurate information, it was necessary to try to co-opt that category and treated them as the target group of this study through making friendships, personal talks and comments on their posts etc. After much effort, we were able to persuade them to add their accounts to a special group and access to their conversations, friends and pages they visited.

After a period of careful follow-up to those accounts with the absence of any control of family or community, we found some of them wasting a long time in useless and indecent chats which oppose the norms, customs and traditions of their society while the other posts instigate violence, sectarianism and regionalism that negatively affect the family and society.

Attempts have been made to convince them to add some of their relatives to their list of friends and to give them the authority to see their chats, comments and posts as well as give a password of their accounts to one of their parents or brothers to $\log$ in. It was found that many of the negative practices that were running among them reduced $100 \%$ with the subscribers who gave their passwords to one of their family members as they got rid of a lot of anonymous friends and suspects. The rest of subscribers who added one of their relatives or close-friends to the list of their friends, bad behavior has gone down $90 \%$, whereas $10 \%$ remained indulged in amoral conduct in personal conversations with friends and get rid of other negative things such as non-useful posts and other behaviors.

To avoid this peril and to reduce it, those privacies granted to subscribers must be limited. Posts, list of friends, and sites visited should be made public. The basic idea of social networking is to spread ideas, pictures and posts among friends. The reduction of confidentiality by social networking companies will prevent a lot of dangers that threaten families and community. These restrictions will prevent adolescents

\section{Volume 5 Issue 3, March 2016}




\section{International Journal of Science and Research (IJSR) \\ ISSN (Online): 2319-7064}

Index Copernicus Value (2013): 6.14 | Impact Factor (2014): 5.611

from going too far in harming themselves and lessen opportunities of terrorists to exploit them in suspicious acts.

On the other hand, social networking companies have infringed the security agreement and violated privacy by selling subscribers' personal information, desires and ideas to advertising companies. At the time these companies have earned huge profits from selling subscribers' information, they withhold it from the families and communities. Each subscriber site will receive different ads according to their posts, likes and sites visited, for example the subscribers who frequently visit the renewable energy manufacture's site, their personal sites contain ads of those manufacturer and supplier products and so on.

That is why we find the social networking companies overall have not given adequate privacy to the subscribers, but exploited them to their profit, gaining significant financial sums without their knowledge.

\section{Conclusion}

Millions of people have taken advantage of social networks through helpful social relationships and the spread of awareness. However, thousands of people if not more have wasted their lives in social networks, some have gone astray, some are brainwashed and got involved in terror acts while others are victimized by fraud.

All this can be easily avoided through adopting the strategy of reducing the authority of subscribers regarding withholding their personal information from their families and society. The privacies that should be public are list of friends, pages visited and comments. Through this strategy, the researchers believe that the risks will be reduced to $90 \%$. This result has been concluded from those subscribers (mentioned in previous section) who refused to display their account names in this research even though their accounts names are not real.

Thus, we recommend social networking companies to minimize the privacy granted to subscribers in order to protect ourselves, our children and our society from prospective risks and catastrophe. Moreover, it should be taken into consideration that any future social programs must include the essential control of family and community over their subscribers.

\section{References}

[1] Buettner, R. Getting a Job via Career-oriented Social Networking Sites: The Weakness of Ties. 49th Annual Hawaii International Conference on System Sciences. Kauai, Hawaii: IEEE. doi:10.13140/RG.2.1.3249.2241,2016.

[2] H. Kietzmann, Jan; Kristopher Hermkens "Social media? Get serious! Understanding the functional building blocks of social media". Business Horizons54: 241-251. doi:10.1016/j.bushor.2011.01.005.
[3] Kirkpatrick, David The Facebook effect: the real inside story of Mark Zuckerberg and the world's fastestgrowing company. London: Virgin. (2011).

[4] https://en.wikipedia.org/wiki/Facebook, Accessed 6 Jan 2016

[5] June Ahn. "The Effect of Social Network Sites on Adolescents' Social and Academic Development", JOURNAL OF THE AMERICAN SOCIETY FOR INFORMATION SCIENCE AND TECHNOLOGY, 62(8):1435-1445. 2011.

[6] https://en.wikipedia.org/wiki/Jack_Dorsey, Accessed 3 Jan 2016.

[7] http://www.biography.com/people/jack-dorsey-578280, Accessed 3 Jan 2016.

[8] Crabbe, Lauren. "Fashion designer brand Michael Kors becomes the first to run ads on Instagram". November 1, 2013.

[9] The Nielsen Company. 2009. How Teens Use Media: A Nielsen report on the myths and realities of teen media trends. Retrieved on May 30, 2011.

[10] http://www.bullguard.com/bullguard-securitycenter/internet-security/social-media-dangers/privacyviolations-in-social-media.aspx, Accessed 3 Jan 2016.

[11] Emailysteel and Geoffery A. Top-Ranked Applications Transmit Personal IDs, wall street journal. 2010.

\section{Author Profile}

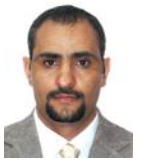

Naif Alsharabi received the B.S. in Computer Science from University of Technology, Baghdad-Iraq in 1997. M.S. and Phd degrees from Hunan University, China in 2005 and 2008 respectively. Currently working as a lecturer in University of Amran-Yemen. His interest area is mobile communication, wireless security and information technology.

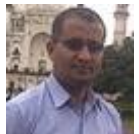

Redhwan Alhilali, received B.A in 2001 from Sana'a university-M.A \& Phd in English from MarthwadaIndia 2011 \& 2014 respectively. Currently working as a lecturer \& head of English language -faculty of languages-Amran university. Interest area is literature and social issues. 